\title{
PERENCANAAN LANSKAP KAWASAN PERKOTAAN KOTA PALU BERBASIS MITIGASI TEMPERATUR PERMUKAAN LAHAN
}

\author{
Landscape Planning Of Urban Area Of Palu City Based On Land Surface Temperature \\ Mitigation
}

\section{Andi Chairul Achsan, Rizkhi, Rezki Awalia}

\author{
Program Studi Perencanaan Wilayah dan Kota, Jurusan Teknik Arsitektur, Fakultas Teknik, \\ Universitas Tadulako
}

Email : andichairulachsan@gmail.com

\begin{abstract}
Urban landscapes have the potential to provide a variety of benefits for urban communities. Urban landscapes can be a public space that can accommodate various kinds of public activities but also can be an ecological space that can provide space or means of protection for the sustainability of natural and environmental resources. The main objective of this study is to develop a landscape plan for the urban area of Palu city based on mitigating land surface temperature. The approach used in this study uses a landscape planning approach which consists of several stages starting from inventory, analysis, synthesis and planning. Based on spatial data on land surface temperature distribution and vegetation density index results obtained showed the highest distribution of temperature distribution in almost all areas of the East Palu Sub District and parts of West Palu Sub District and the lowest temperature distribution was in parts of West Palu Sub District. Based on the results of the spatial analysis of land surface temperature distribution and vegetation density index, the results show that landscape development plans with intensive green arrangement intensity are located in the East Palu Sub District and part of West Palu Sub District and landscape development plans with the intensity of non-intensive green is located on Most of the West Palu Sub District Area.
\end{abstract}

Key Words : Planning, Landscape, Urban, Temperature, Mitigation

\section{ABSTRAK}

Lanskap perkotaan memiliki potensi untuk memberikan berbagai macam manfaat bagi masyarakat perkotaan. Lanskap perkotaan dapat menjadi ruang publik yang dapat mewadahi berbagai macam aktivitas publik sekaligus juga menjadi ruang ekologis yang dapat memberikan ruang atau sarana perlindungan bagi keberlanjutan sumberdaya alam dan lingkungan. Tujuan utama dari penelitian ini adalah menyusun rencana lanskap kawasan perkotaan kota palu berbasis mitigasi temperatur permukaan lahan. Pendekatan yang digunakan dalam penelitian ini menggunakan pendekatan perencanaan lanskap yang terdiri dari beberapa tahapan mulai dari inventarisasi, analisis, sintesis dan perencanaan. Berdasarkan data spasial distribusi temperatur permukaan lahan dan indeks kerapatan vegetasi diperoleh hasil yang menunjukkan sebaran distribusi suhu tertinggi berada pada hampir seluruh wilayah Kecamatan Palu Timur dan sebagian wilayah Kecamatan Palu Barat dan distribusi suhu terendah berada pada sebagian wilayah Kecamatan Palu Barat. Berdasarkan hasil analisis spasial distribusi temperatur permukaan lahan dan indeks kerapatan vegetasi diperoleh hasil yang menunjukkan rencana pengembangan lanskap dengan intensitas penataan tata hijau intensif berada pada wilayah Kecamatan Palu Timur dan sebagian wilayah Kecamatan Palu Barat dan rencana pengembangan lanskap dengan intensitas penataan tata hijau non intensif berada pada sebagian wilayah Kecamatan Palu Barat.

Kata Kunci : Perencanaan, Lanskap, Perkotaan, Temperatur, Mitigasi 


\section{PENDAHULUAN}

\section{A. Latar Belakang}

Kawasan perkotaan terus menunjukkan perkembangan yang cukup pesat. Jumlah penduduk yang terus bertambah mengakibatkan kebutuhan lahan untuk mewadahi aktivitas penduduk juga terus bertambah utamanya yang terkait dengan kebutuhan permukiman, pusat-pusat perdagangan dan jasa, industri serta berbagai fasilitas lainnya. Pertumbuhan berbagai fasilitas ini mengakibatkan jumlah lahan terbangun menjadi bertambah dan cenderung hampir memenuhi seluruh wilayah kota diakibatkan luas wilayah kota yang terbatas dan orientasi pembangunan cenderung tersebar. Kawasan perkotaan yang hampir dipenuhi oleh fasilitas fisik perkotaan dapat berdampak pada menurunnya kualitas lingkungan. Salah satu isu lingkungan yang sedang berkembang adalah isu pemanasan global yang ditandai dengan semakin meningkatnya suhu sebagai akibat dari aktivitas pembangunan yang tidak terkendali.

Kota Palu memiliki suhu rata-rata yang relatif tinggi. Kondisi ini dipengaruhi oleh faktor alami maupun buatan. Secara alami suhu yang relatif tinggi dipengaruhi oleh kondisi geografis wilayah namun secara buatan faktor perkembangan pembangunan diwilayah perkotaan juga menjadi faktor yang dapat berkontribusi terhadap peningkatan suhu. Penataan wilayah perkotaan Kota Palu cenderung belum memperhatikan aspek iklim khususnya suhu. Wilayah perkotaan Kota Palu hampir dipenuhi oleh kawasan terbangun namun disisi lain penataan diluar kawasan terbangun belum menjadi perhatian sebagai bagian dari fasilitas publik sekaligus juga sebagai ruang pengendali lingkungan.

Optimalisasi kawasan perkotaan adalah kawasan yang dapat memfasilitasi kebutuhan masyarakat pada berbagai aspek guna tercipta kawasan perkotaan yang fungsional. Perkembangan kawasan perkotaan dengan tantangan pertumbuhan penduduk yang terus meningkat menuntut penataan kawasan perkotaan yang terus memberikan ruang untuk penyediaan fasilitas tetapi juga tetap menjaga kestabilan lingkungan agar tercipta harmonisasi hubungan antara manusia dan lingkungan. Berkaitan dengan permasalahan belum optimalnya penataan kawasan perkotaan khususnya dalam kaitannya dengan penciptaan iklim kota yang ideal perlu disusun model penataan kawasan perkotaan melalui penataan lanskap kawasan perkotaan secara optimal.

\section{B. Urgensi Penelitian}

Pembangunan perkotaan di Indonesia masih memiliki tantangan. Kualitas lingkungan merupakan salah satu isu atau permasalahan yang sering ditemui pada kota-kota di Indonesia saat ini. Berbagai bentuk permasalahan dapat ditemukan hampir di seluruh kotakota di Indonesia baik melalui media cetak, elektronik maupun melalui pengamatan secara langsung di lapangan. Aktivitas perkotaan yang cenderung tidak terkendali merupakan salah satu isu yang mendasari timbulnya permasalahan terkait menurunnya kualitas lingkungan. Oleh karena itu diperlukan upaya pengendalian wilayah perkotaan dengan tidak hanya berfokus pada pemenuhan kebutuhan pada sektor tertentu tanpa memperhatikan dampaknya terhadap sektor lain.

Pemerintah pusat dan daerah mengharapkan kota-kota di Indonesia dapat menjadi kota yang cerdas dalam arti kota yang dapat meningkatkan produktivitas bagi warganya melalui penataan kota dalam berbagai aspek. Kota palu sebagai salah satu kota yang sedang berkembang diharapkan dapat menjadi model kota cerdas bagi kota-kota lainnya di Indonesia. Kota Palu sejak dini diupayakan untuk pengembangan kawasan perkotaanya dapat mengantisipasi kemungkinan-kemungkinan dampak negatif yang mungkin terjadi yang dapat mengurangi produktivitas dari warga kota itu sendiri. Penelitian ini diharapkan dapat menjadi model dalam mewujudkan kota yang antisipatif dan responsif terhadap kemungkinan-kemungkinan yang terjadi sehingga dapat dihasilkan suatu kota yang produktif dan berkelanjutan. 


\section{Rumusan Masalah}

Lanskap perkotaan dapat berperan bagi terciptanya suatu ruang publik yang dapat mendukung berbagai aktivitas publik warga kota sekaligus juga menjadi ruang ekologis bagi terciptanya kualitas lingkungan perkotaan yang memadai. Salah satu aspek lingkungan yang dapat berpengaruh bagi keberlanjutan dan kenyamanan wilayah perkotaan adalah aspek suhu. Aktivitas diruang publik dirasakan tidak dapat terlaksana secara optimal jika suhu pada kawasan tersebut cenderung tidak memadai atau memiliki suhu yang cukup tinggi. Pembangunan wilayah kota khususnya pada wilayah perkotaan yang cenderung didominasi oleh elemen fisik dapat berkontribusi terhadap peningkatan suhu perkotaan yang pada akhirnya dapat berakibat pada menurunnya kenyamanan warga dalam beraktivitas.

Wilayah perkotaan Kota Palu saat ini secara geografis memiliki kondisi iklim yang relatif panas, kondisi ikilim seperti ini tentunya dapat berpengaruh terhadap kenyamanan warga dalam beraktivitas sehingga dalam penataan kawasan wilayah perkotaan hendaknya perlu memperhatikan aspek iklim namun kondisi yang terjadi saat ini terlihat di beberapa titik diwilayah perkotaan Kota Palu penataan masih belum optimal khususnya yang terkait dengan penataan lanskap seperti minimnya elemen vegetasi. Belum optimalnya penataan lanskap ini berimplikasi terhadap masih minimnya pemanfaatan ruang publik oleh warga.

Berdasarkan kondisi permasalahan di atas dapat dirumuskan pertanyaan penelitian yaitu bagaimana distribusi suhu permukaan lahan kawasan perkotaan Kota Palu serta bagaimana model perencanaan lanskap kawasan perkotaan sebagai upaya mitigasi temperatur permukaan lahan kawasan perkotaan Kota Palu.

\section{Tujuan Penelitian}

Tujuan utama dari penelitian ini adalah menyusun rencana lanskap kawasan perkotaan Kota Palu berbasis mitigasi temperatur permukaan lahan. Tujuan khusus penelitian meliputi

1. Menganalisis dan menentukan distribusi temperatur permukaan lahan kawasan perkotaan Kota Palu

2. Menganalisis indeks kerapatan vegetasi kawasan perkotaan Kota Palu

3. Memformulasikan konsep dan menyusun rencana lanskap kawasan perkotaan berdasarkan distribusi temperatur permukaan lahan

\section{E. Lingkup dan Batasan Penelitian}

Untuk mendapatkan fokus dari penelitian yang dapat mengarahkan pada tujuan yang akan dicapai, maka penelitian ini memiliki batasan-batasan sebagai berikut:

- Faktor yang berpengaruh terhadap perencanaan difokuskan pada dua aspek yaitu aspek disribusi temperatur permukaan lahan dan indeks kerapatan vegetasi

- Pengukuran distribusi temperatur permukaan lahan dan indeks kerapatan vegetasi dilakukan dengan menggunakan aplikasi komputer, tidak dilakukan pengukuran lapangan, pengamatan lapangan dilakukan untuk menyesuaikan kondisi hasil simulasi dengan kondisi lokasi penelitian

- Perencanaan lanskap difokuskan pada pengaturan tata hijau kawasan 


\section{METODE}

\section{A. Lokasi dan Waktu}

Penelitian dilakukan di wilayah perkotaan Kota Palu yaitu wilayah Kecamatan Palu Timur dan Palu Barat Kota Palu, Provinsi Sulawesi Tengah. Penelitian dilaksanakan selama 8 bulan dimulai sejak bulan April sampai dengan November 2018.

\section{B. Alat dan Bahan}

Alat-alat yang digunakan dalam penelitian ini adalah seperangkat komputer, alat tulis dan perangkat lunak (software) untuk penyusunan naskah, pengolahan dan analisis data. Perangkat lunak yang digunakan terdiri dari Arc GIS 10.0, Microsoft Office dan Excell 2007. Bahan yang diperlukan untuk penelitian ini berupa citra satelit landsat 8 oli tirs Kota Palu.

\section{Data dan Jenis Data}

Data yang digunakan terdiri dari data primer dan data sekunder. Data primer meliputi kondisi lokasi penelitian berupa data pemanfaatan lahan yang akan digunakan sebagai data pembanding hasil pengukuran temperatur permukaan lahan menggunakan sistem informasi geografis. Data sekunder berupa data statistik penduduk, iklim, luas wilayah, penggunaan lahan serta beberapa data pendukung lainnya.

\section{Teknik Pengumpulan Data}

Pengumpulan data primer diperoleh dengan cara observasi ke lokasi atau obyek penelitian serta melakukan diskusi dan wawancara langsung dengan stakeholder. Data sekunder diperoleh dengan cara menelusuri berbagai sumber seperti hasil penelitian dan dokumen ilmiah dari instansi terkait.

\section{E. Analisis Data}

Analisis data terdiri dari :

1. Analisis distribusi temperatur permukaan lahan kawasan perkotaan Kota Palu.

Analisis penentuan temperatur permukaan kawasan perkotaan Kota Palu menggunakan citra landsat 8 oli tirs tahun 2018 band 10 dan 11, citra ini dikonversi kedalam bentuk radiance dan selanjutnya dikonversi ke dalam format temperatur.

1. Konversi Digital Number ke dalam Radian Spektral :

$\mathrm{L} \lambda=\operatorname{Lmin}(\lambda)+\{\operatorname{Lmax}(\lambda)-\operatorname{Lmin}(\lambda) / \mathrm{Qmax}\} \times \mathrm{QDN} \ldots(1)$

Dimana: $\mathrm{L} \lambda$ : Radian Spektral $\mathrm{Lmax}(\lambda)$ : Maximum spectral radiance $\mathrm{Lmin}(\lambda)$ :

Minimum spectral radiance QDN : Digital Number Qmax : Nilai Maksimum Digital

Number

2. Konversi Radian Spektral menjadi Kelvin

$$
T b=\frac{K_{2}}{\ln \left(\frac{K_{1}}{L_{\lambda}}+1\right)} \ldots \ldots \text { (2) }
$$

Dimana : Tb : Brightness Temperature satelit $(\mathrm{K}) \mathrm{K} 1$ : Konstanta kalibrasi radian spektral K2 : Konstanta kalibrasi suhu absolut (K) : Radian spektral

3. Konversi suhu dalam satuan Kelvin menjadi Celcius

T Celcius $=$ T Kelvin-273

2. Analisis penentuan kerapatan vegetasi

Dalam menghitung indeks kerapatan vegetasi NDVI (Normalized Difference Vegetation Index), band merah mewakili spektrum tampak dibandingkan dengan spektrum inframerah NIR (Near-Infrared Radiation). Persamaan dibawah menjelaskan metode menghitung NDVI (Lillesand T.M., Kiefer R.W., 2000) 


$$
N D V I=(\rho N I R-\rho R E D) /(\rho N I R+\rho R E D)
$$

dimana: $\rho$ NIR : Nilai radiance saluran Inframerah, $\rho R E D$ : Nilai radiance spektrum tampak merah.

3. Rencana pengembangan lanskap kawasan perkotaan Kota Palu.

Perencanaan lanskap kawasan perkotaan Kota Palu didasarkan pada distribusi spasial temperatur permukaan lahan dan indeks kerapatan vegetasi.

\section{HASIL dan PEMBAHASAN}

\section{A. Analisis Penentuan Distribusi Temperatur Permukaan Lahan Kawasan Perkotaan Kota Palu}

Temperatur permukaan tanah atau Land Surface Temperature (LST) merupakan keadaan yang dikendalikan oleh keseimbangan energi permukaan, atmosfer, sifat termal dari permukaan dan media bawah permukaan tanah. Temperatur permukaan suatu wilayah dapat diidentifikasikan dari citra satelit Landsat yang diekstrak dari band thermal (Utomo dkk, 2017). Penentuan distribusi temperatur permukaan lahan dilakukan dengan beberapa tahapan yaitu mengakses data dimana data yang digunakan menggunakan data citra satelit landsat 8 tahun 2018 yang diperoleh melalui USGS (United States Of Geological Survey).

Data citra satelit yang didapatkan tidak dapat langsung diolah digital numbernya, namun harus mengalmi beberapa tahapan konversi terlebih dahulu untuk mendapatkan nilai suhu permukaan yang sebenarnya. Algoritma yang digunakan adalah Mono window Brightness Temperature (USGS dalam Mukmin dkk 2016)

Dalam penentuan distribusi temperatur permukaan lahan menggunakan data band 10 dan band 11 yang ada pada data citra, tahap selanjutnya adalah menambahkan data dan mengolah data ke dalam aplikasi ArcGIS, data yang di tambahkan dipotong sesuai dengan wilayah studi untuk kemudian dilakukan proses konversi menggunakan formula yang ada ke dalam format radiance untuk selanjutnya diubah ke dalam format satellite temperature.

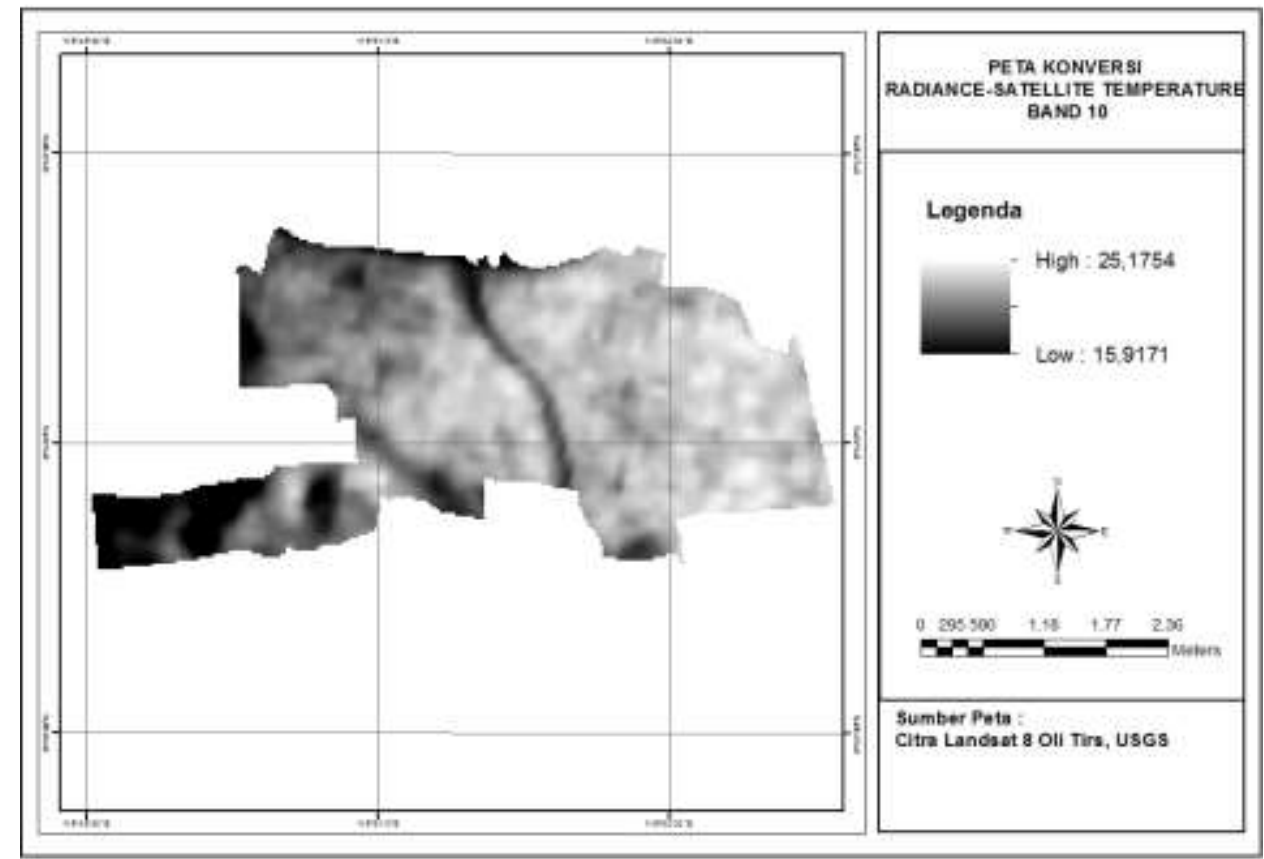

Gambar 1. Peta Konversi Citra Landsat Band 10 Ke dalam Radiance Figure 1. Landsat Band 10 Image Conversion Map in Radiance 


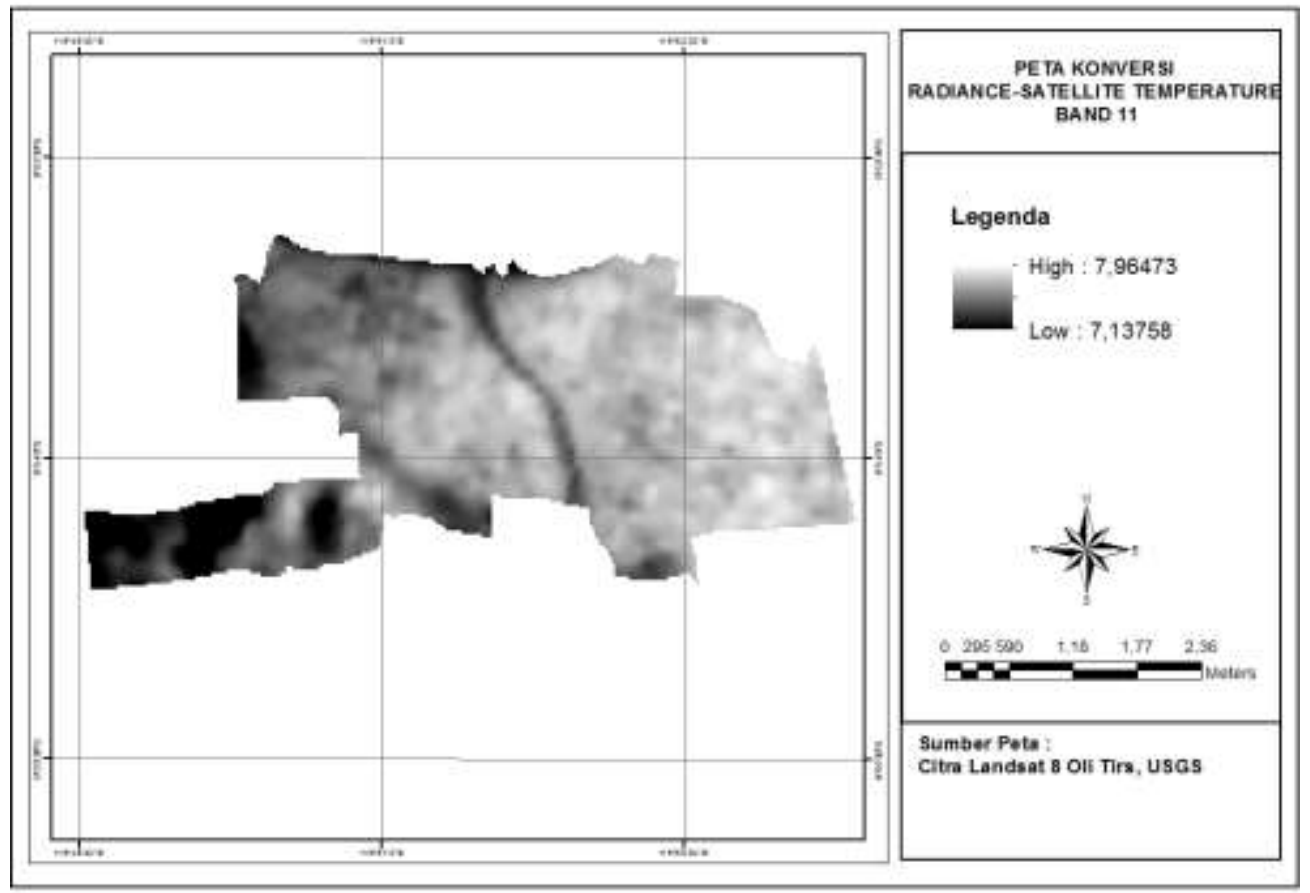

Gambar 2. Peta Konversi Cita Landsat Band 11 Ke dalam Radiance Figure 2. Landsat Band 11 Image Conversion Map in Radiance

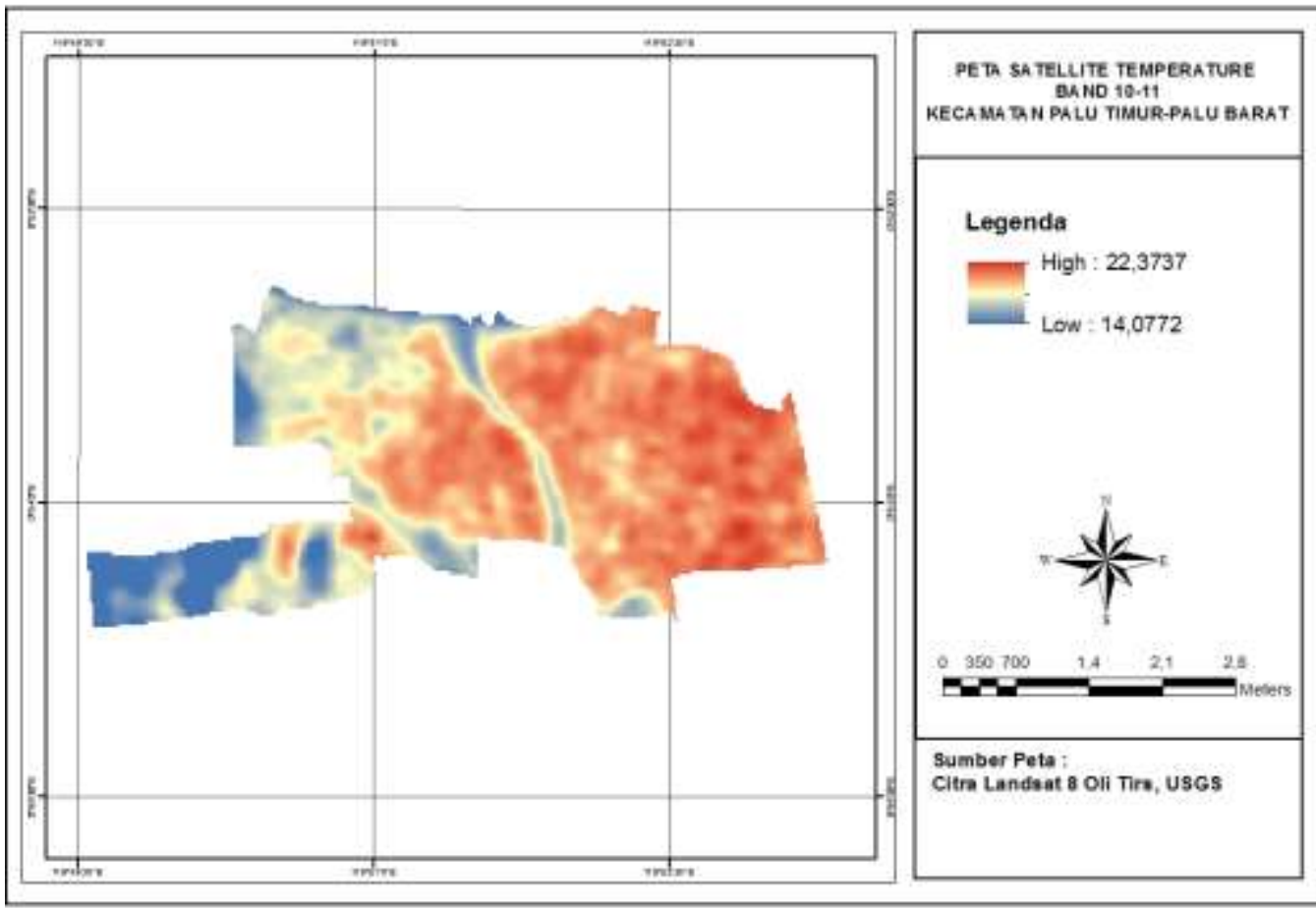

Gambar 3. Peta Distribusi Temperatur Permukaan Lahan Kawasan Perkotaan Kota Palu Figure 3. Map of Surface Temperature Distribution of Urban Area of Palu City

Hasil konversi yang diperoleh menunjukkan nilai radiance pada band 10 nilai tertinggi yaitu 25,16 dan terendah yaitu 15,92 sedangkan pada band 11 menunjukkan nilai teringgi yaitu 7,96 dan terendah 7,14 . Hasil konversi nilai radiance kedalam format temperatur berdasarkan data band 10 dan band 11 menunjukkan nilai suhu tertinggi sebesar $22,37^{\circ} \mathrm{C}$ dan terendah sebesar $14,07^{\circ} \mathrm{C}$. Berdasarkan data spasial distribusi temperatur permukaan 
lahan diperoleh hasil yang menunjukkan sebaran distribusi suhu tertinggi berada pada hampir seluruh wilayah Kecamatan Palu Timur dan sebagian wilayah Kecamatan Palu Barat dan distribusi suhu terendah berada pada sebagian wilayah Kecamatan Palu Barat.

Distribusi temperatur permukaan lahan yang dihasilkan menunjukkan pada wilayah yang memiliki nilai suhu tinggi berada pada wilayah yang didominasi oleh kawasan terbangun sedangkan yang memiliki suhu rendah tidak sepenuhnya didominasi oleh area terbangun namun masih tersedia area hijau. Pada dasarnya, penggunaan lahan dapat berpengaruh terhadap penerimaan radiasi matahari dan kemampuan bahan penutup lahan tersebut dalam melepaskan panas yang diterima dari radiasi matahari (Fajri, 2011). Konsentrasi penduduk pada wilayah tertentu ditambah dengan adanya industri dan perdagangan serta transportasi kota yang padat menyebabkan terjadinya thermal pollution yang kemudian membentuk pulau panas atau heat island (Setyowati, 2008). Heat island merupakan suatu fenomena atau kejadian peningkatan suhu udara di wilayah perkotaan dibandingkan dengan daerah di sekitarnya hingga mencapai 3-10 ำ. Fenomena ini disebabkan oleh adanya perubahan tata guna lahan dari vegetasi menjadi daerah yang beraspal, beton dan lahan terbuka (Khomarudin, 2004). Keberadaan vegetasi atau permukaan air dapat menurunkan temperature karena sebagian energi radiasi matahari yang diserap permukaan akan dimanfaatkan untuk menguapkan air dari jaringan tumbuhan (transpirasi) atau langsung dari permukaan air atau permukaan padat yang mengandung air (evaporasi), perubahan lahan menjadi wilayah permukiman juga akan menyebabkan temperature permukaan yang tinggi (Fracilia, 2007).

\section{B. Analisis Penentuan Indeks Kerapatan Vegetasi Kawasan Perkotaan Kota Palu}

Penentuan nilai indeks kerapatan vegetasi merupakan analisis lanjutan sekaligus menjadi penunjang bagi analisis penentuan distribusi temperatur permukaan lahan untuk melihat sejauh mana kesesuaian dari analisis penentuan distribusi temperatur permukaan lahan terhadap kerapatan vegetasi dimana dapat diasumsikan nilai distribusi temperatur yang tinggi memiliki nilai kerapatan vegetasi yang rendah. Indeks kerapatan vegetasi atau NDVI (Normalized Difference Vegetation Index) adalah indeks yang menggambarkan tingkat kehijauan suatu tanaman. Indeks vegetasi merupakan kombinasi matematis antara band merah dan band NIR (Near-Infrared Radiation) yang telah lama digunakan sebagai indikator keberadaan dan kondisi vegetasi (Lillesand dan Kiefer dalam Putra dkk. 2018).

Penentuan nilai indeks keragaman vegetasi dilakukan menggunakan data citra landsat 8 band 4 dan band 5, data yang diperoleh di tambahkan dan dipotong sesuai dengan delineasi wilayah studi, selanjutnya data dianalisis menggunakan formula yang telah ditentukan untuk mendapatkan nilai NDVI atau nilai indeks kerapatan vegetasi. Berdasarkan hasil analisis yang diperoleh menunjukkan nilai kerapatan tertinggi sebesar 0,534 dan terendah sebesar $-0,128$.

Berdasarkan data spasial kerapatan vegetasi diperoleh hasil yang menunjukkan sebaran kerapatan vegetasi tinggi berada pada hampir seluruh wilayah Kecamatan Palu Timur dan sebagian wilayah Kecamatan Palu Barat dan kerapatan vegetasi rendah berada pada sebagian wilayah Kecamatan Palu Barat. Hasil yang diperoleh pada penentuan nilai indeks keragaman vegetasi menunjukkan kesesuaian antara hasil yang diperoleh pada analisis penentuan distribusi temperatur permukaan lahan dan analisis penentuan kerapatan vegetasi. Panas permukaan terbentuk jika sebagian tumbuh-tumbuhan (vegetasi) digantikan oleh aspal dan beton untuk jalan, bangunan dan struktur lain yang diperlukan untuk mengakomodasi pertumbuhan jumlah penduduk yang tinggi. Permukaan tanah yang tergantikan tersebut akan lebih banyak menyerap panas Matahari dan memantulkannya, sehingga menyebabkan suhu permukaan daratan di kota itu naik (Adiyanti dalam Nugroho dkk. 2016) 


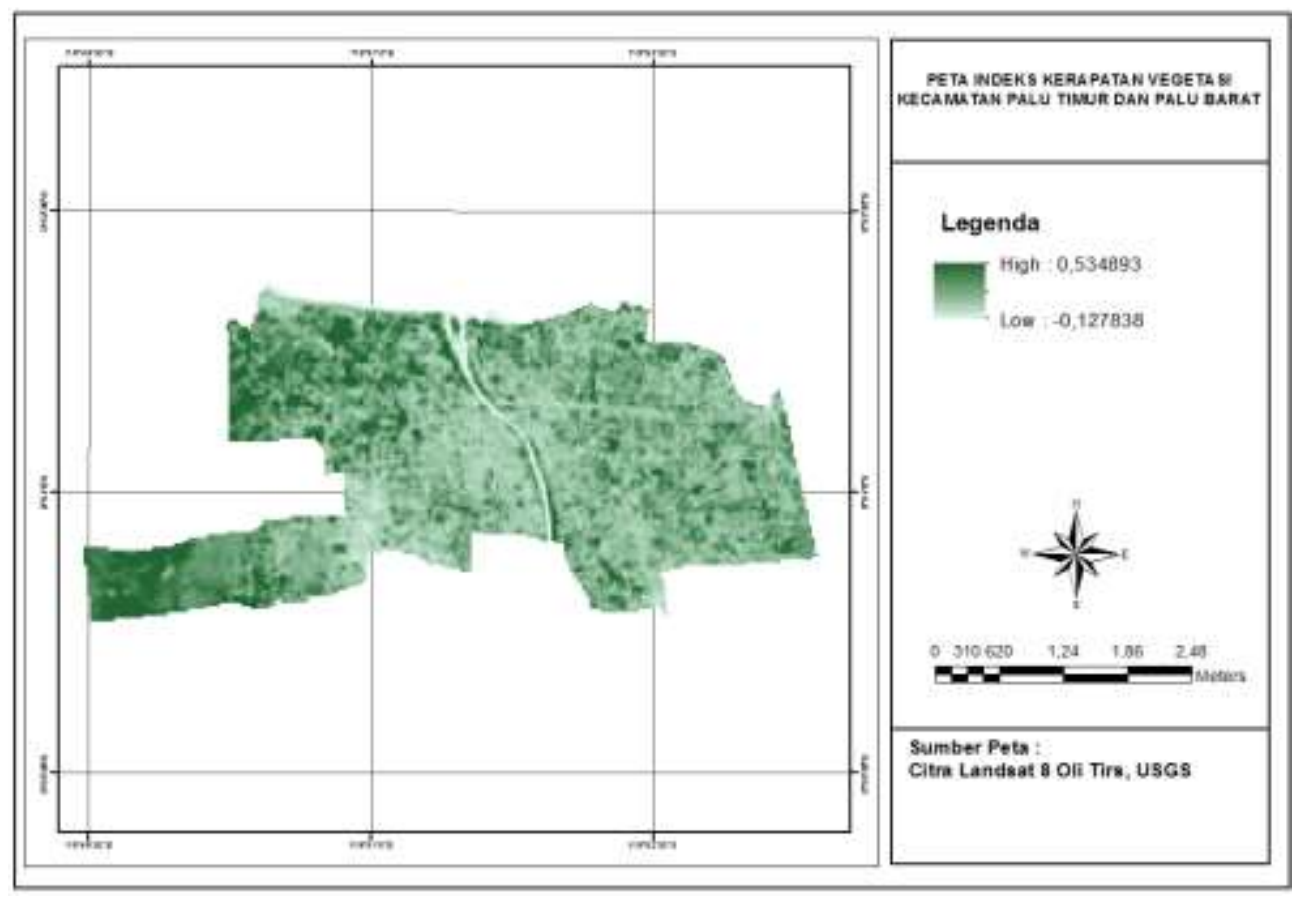

Gambar 4. Peta Indeks Kerapatan Vegetasi Kawasan Perkotaan Kota Palu Figure 4. Map of the density index of vegetation in urban areas of the city of Palu

\section{Perencanaan Lanskap Kawasan Perkotaan Kota Palu Berbasis Mitigasi Temperatur Permukaan Lahan}

Perencanaan (planning) adalah suatu proses pengambilan keputusan yang berorientasi pada kepentingan dan kebutuhan masa yang akan datang. Proses perencanaan ini, menurut Simonds (1983), adalah suatu alat sistematik yang digunakan untuk menentukan saat awal, keadaan yang diharapkan dan cara terbaik untuk mencapai keadaan itu. Lanskap berasal dari kata "land" dan "scape" yang artinya pada suatu lanskap terdapat hubungan totalitas anatara karakter biofisik, ekologis, dan geografis serta berlangsung proses integrasi pola hubungan antara manusia dengan alam (Laurie, 1986). Dalam perencanaan, diperlukan suatu pendekatan yang dilakukan terhadap kebutuhan khusus dari suatu kelompok sosial atau lahan. Pendekatannya harus efektif untuk penyediaan segala bentuk pelayanan dan ruang bagi masyarakat yang menggunakannya (Siti Nurisjah dan Pramukanto, 1995). Lebih lanjut dinyatakan bahwa proses perencanaan lanskap diawali dengan memperhatikan, menafsirkan dan menjawab kepentingan manusia dengan mengakomodasikan berbagai kepentingan ini ke produk (lahan) yang direncanakan seperti antara lain untuk mengkreasikan dan merencanakan secara fisik berbagai bentuk pelayanan, fasilitas, dan berbagai bentuk pemanfaatan sumber daya tersedia lainnya dan nilai-nilai budaya manusia (Siti Nurisjah dan Pramukanto, 1995)

Perencanaan lanskap kawasan perkotaan Kota Palu didasarkan pada distribusi spasial temperatur permukaan lahan dan indeks kerapatan vegetasi. Perencanaan lanskap pada area studi difokuskan pada penataan tata hijau kawasan sebagai elemen yang diharapkan dapat mereduksi suhu permukaan. Berdasarkan hasil analisis spasial distribusi temperatur permukaan lahan dan indeks kerapatan vegetasi diperoleh hasil yang menunjukkan rencana pengembangan lanskap dengan intensitas penataan tata hijau intensif berada pada wilayah Kecamatan Palu Timur dan sebagian wilayah Kecamatan Palu Barat dan rencana pengembangan lanskap dengan intensitas penataan tata hijau non intensif berada pada sebagian wilayah Kecamatan Palu Barat. 


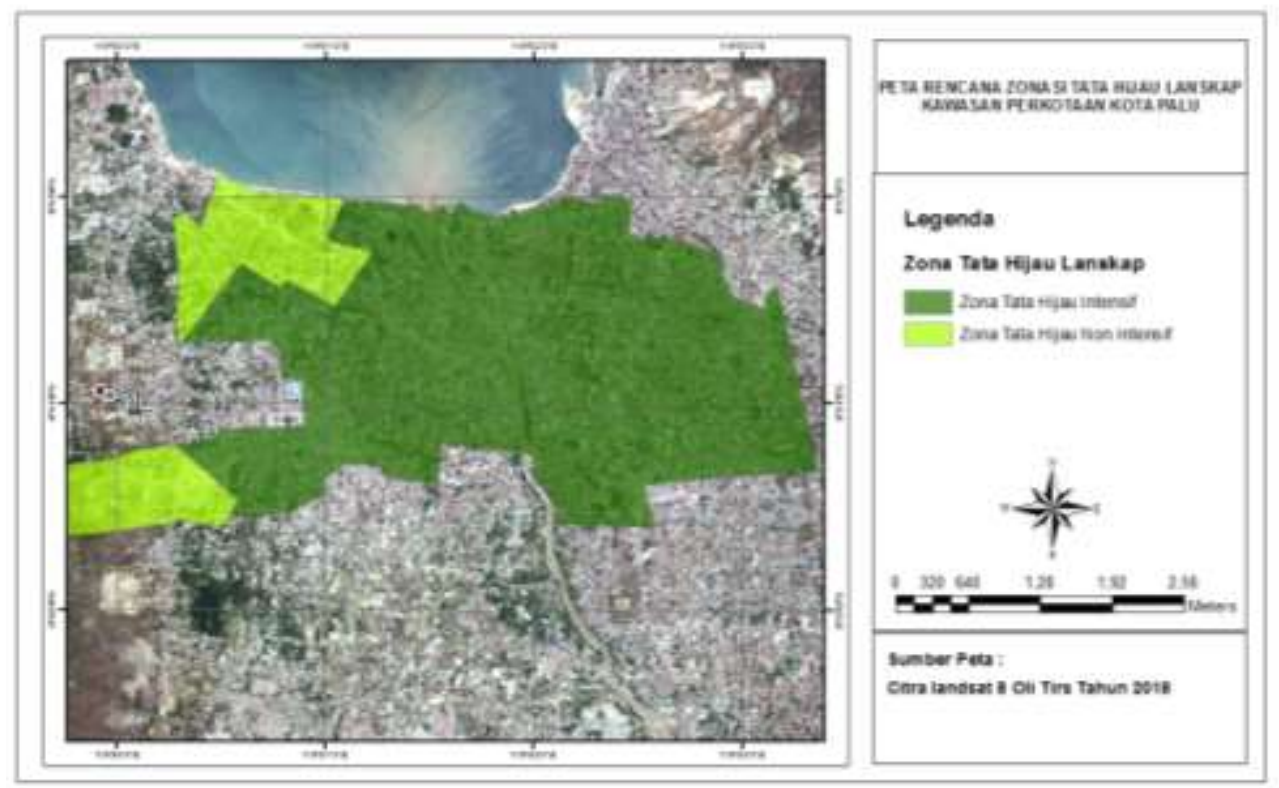

Gambar 5. Peta Rencana Zonasi Tata Hijau Lanskap Kawasan Perkotaan Kota Palu Figure 5. Map of Zoning Planning for Green Lands in Urban Areas of Palu City

\section{KESIMPULAN dan SARAN}

\section{A. Kesimpulan}

1. Berdasarkan data spasial distribusi temperatur permukaan lahan diperoleh hasil yang menunjukkan sebaran distribusi suhu tertinggi berada pada hampir seluruh wilayah Kecamatan Palu Timur dan sebagian wilayah Kecamatan Palu Barat dan distribusi suhu terendah berada pada sebagian wilayah Kecamatan Palu Barat.

2. Distribusi temperatur permukaan lahan yang dihasilkan menunjukkan pada wilayah yang memiliki nilai suhu tinggi berada pada wilayah yang didominasi oleh kawasan terbangun sedangkan yang memiliki suhu rendah tidak sepenuhnya didominasi oleh area terbangun namun masih tersedia area hijau

3. Berdasarkan data spasial kerapatan vegetasi diperoleh hasil yang menunjukkan sebaran kerapatan vegetasi tinggi berada pada hampir seluruh wilayah Kecamatan Palu Timur dan sebagian wilayah Kecamatan Palu Barat dan kerapatan vegetasi rendah berada pada sebagian wilayah Kecamatan Palu Barat. Hasil yang diperoleh pada penentuan nilai indeks keragaman vegetasi menunjukkan kesesuaian antara hasil yang diperoleh pada analisis penentuan distribusi temperatur permukaan lahan dan analisis penentuan kerapatan vegetasi.

4. Perencanaan lanskap kawasan perkotaan Kota Palu didasarkan pada distribusi spasial temperatur permukaan lahan dan indeks kerapatan vegetasi. Perencanaan lanskap pada area studi difokuskan pada penataan tata hijau kawasan sebagai elemen yang diharapkan dapat mereduksi suhu permukaan. Berdasarkan hasil analisis spasial distribusi temperatur permukaan lahan dan indeks kerapatan vegetasi diperoleh hasil yang menunjukkan rencana pengembangan lanskap dengan intensitas penataan tata hijau intensif berada pada wilayah Kecamatan Palu Timur dan sebagian wilayah Kecamatan Palu Barat dan rencana pengembangan lanskap dengan intensitas penataan tata hijau non intensif berada pada sebagian wilayah Kecamatan Palu Barat. 


\section{B. Saran}

Diperlukan penelitian lanjutan untuk melihat hubungan antara pemanfaatan ruang kawasan perkotaan yang lebih detail dari segi kenampakannya pada citra terhadap distribusi temperatur permukaan lahan sehingga dapat ditentukan rencana lanskap yang lebih spesifik pula dalam kaitannya dengan peningkatan kenyamanan.

\section{DAFTAR PUSTAKA}

Fajri PYN. 2011. Pemodelan Pengaruh Jarak Jangkau Ruang Terbuka Hijau Terhadap Suhu Permukaan di Perkotaan (Studi Kasus: Kota Bogor) [Skripsi]. Bogor: Departemen Geofisika Dan Meteorologi Fakultas Matematika Dan Ilmu Pengetahuan Alam, Institut Pertanian Bogor.

Fracillia L. 2007. Analisis Korelasi Ruang Terbuka Hijau dan Temperatur Permukaan dengan SIG dan Penginderaan Jauh (Studi Kasus: DKI).

Laurie, M., 1984. An Introduction to Landscape Architecture. Dept of Landscape Architecture, University of California, Berkeley.

Lillesand T.M., and Kiefer R.W., 2000. Remote Sensing and Image Interpretation. Second Edition, John Wiley \& Sons, New York

Mukmin, S.A., Wijaya, A.P., Sukmono A. 2016. Analisis Pengaruh Perubahan Tutupan Lahan Terhadap Distribusi Suhu Permukaan Dan Keterkaitannya Dengan Fenomena Urban Heat Island. Jurnal Geodesi Undip Volume 5, Nomor 1, Tahun 2016.

Nurisjah, S. dan Pramukanto, Q. 1995. Penuntun Praktikum Perencanaan Lansekap. Jurusan Budidaya Pertanian. Fakultas Pertanian, Jurusan Budidaya Pertanian. Fakultas Pertanian. Institut Pertanian Bogor.

Nugroho,S.A., Wijaya, A.P., Sukmono A. 2016. Analisis Pengaruh Perubahan Vegetasi Terhadap Suhu Permukaan Di Wilayah Kabupaten Semarang Menggunakan Metode Penginderaan Jauh. Jurnal Geodesi Undip. Volume 5, Nomor 1, Tahun 2016.

Putra, A.K., Sukmono, A., Sasmito, B. 2018. Analisis Hubungan Perubahan Tutupan Lahan Terhadap Suhu Permukaan Terkait Fenomena Urban Heat Island Menggunakan Citra Landsat (Studi Kasus Kota Surakarta). Jurnal Geodesi Universitas Diponegoro. Volume 3 No. 7 Tahun 2018 (ISSN : 2337-845x).

Prasasti I. 2004. Analisis Hubungan Penutupan Lahan dan Parameter Turunan Data Penginderaan Jauh dengan Albedo Permukaan [Tesis]. Bogor: Sekolah Pascasarjana, Institut Pertanian Bogor.

Simonds, J.O., 1983. Landscape Architecture. McGraw Hill Book Co., New York.

Setyowati DL. 2008. Iklim Mikro dan Kebutuhan Ruang Terbuka Hijau di Kota Semarang. Jurnal Manusia dan Lingkungan. Vol 15 (3): 125-140.

Khomarudin MK. 2004. Mendeteksi Pulau Panas (Heat Island) dengan Data Satelit Penginderaan Jauh. Warta LAPAN Vol.6 (2): 74-81.

Utomo, A.W., Suprayogi A., Sasmito B. 2017. Analisis Hubungan Variasi Land Surface Temperature Dengan Kelas Tutupan Lahan Menggunakan Data Citra Satelit Landsat (Studi Kasus : Kabupaten Pati). Jurnal Geodesi Undip Volume 6 Nomor 2 Tahun 2017. 